\title{
Совершенствование
}

\section{инструментария оценки финансового потенциала отрасли электроэнергетики}

\author{
Инна Николаевна Рыкова \\ доктор экономических наук, руководитель \\ ORCID \\ E-mail: rycova@yandex.ru \\ Центр отраслевой экономики, «Научно-исследовательский финансовый институт» Министерства финансов \\ Российской Федерации, Москва, Россия
}

\section{Денис Юрьевич Табуров}

кандидат технических наук, старший научный сотрудник

ORCID

E-mail: taburov@narod.ru

Центр отраслевой экономики, «Научно-исследовательский финансовый институт» Министерства финансов Российской Федерации, Москва, Россия

Journal of Corporate Finance Research, Vol. 13, No. 1, pp. 93-106 (2019)

DOI: https://doi.org/10.17323/j.jcfr.2073-0438.13.1.2019.93-106

Поступила в редакцию 18 октября 2018 | Получена рецензия 15 декабря 2018 |

Принята к публикации 5 марта 2019 


\section{Совершенствование инструментария оценки финансового потенциала отрасли электроэнергетики}

\section{Аннотация}

Влияние внешних и внутренних факторов на экономику компаний приводит к изменению финансового потенциала отрасли электроэнергетики и недостаточно полной оценке активности компаний ее электроэнергетики для повышения эффективности управления ресурсами, что обусловило актуальность проведения данного исследования. В качестве объекта исследования выбран вид экономической деятельности, который относится к производству, передаче и перераспределению электроэнергии для измерения финансового потенциала и поиска резервов повышения вклада в экономический рост страны.

Цель исследования состоит в оценке финансового потенциала отрасли как источника роста экономики, а также возможностей прогнозирования развития экономики в электроэнергетике.

В статье рассмотрены источники финансирования инвестиций в основной капитал в отрасли электроэнергетики в Российской Федерации, определена динамика параметров, воздействующих на уровень финансового потенциала компаний отрасли электроэнергетики, проиллюстрирована динамика стоимости инвестиций в денежном эквиваленте в соотношении с оборотом энергетических компаний. На основе проведенного исследования авторами разработаны модель гибкого развития и финансирования компаний реального сектора экономики (на примере компаний электроэнергетики) и методические рекомендации по формированию конкурентного механизма финансирования компаний электроэнергетики.

Новизна предлагаемой модели заключается в расширении возможностей по инвестированию в отрасль электроэнергетики как на региональном, так и на федеральном уровне и направлена на повышение финансового потенциала компаний - инициаторов проекта. Проведенный анализ позволил выделить четыре типа инструментов финансирования, которые рекомендуется применять для совершенствования деятельности компаний реального сектора экономики: инструменты государственно-частного партнерства, инновационного развития, государственной экономической политики и фискальные инструменты.

Практическая значимость разработанных методических рекомендаций заключается в том, что их адаптация к компаниям реального сектора экономики позволит усовершенствовать стратегическое управление финансовым механизмом аккумулирования потоков доходов таких компаний в долгосрочной перспективе и выработать модель гибкого планирования бюджета и оценки ключевых рисков, возникающих на всех уровнях экономического развития.

Ключевые слова: финансовый потенциал, электроэнергетика, реальный сектор экономики

JEL-классификация: E60, G32, Q40, Q41, Q48 


\section{Финансовый потенциал отрасли: теория}

Финансовый потенциал отрасли можно рассматривать через призмы разных научных взглядов, большинство ученых использует совокупность терминов и понятий исходя из совокупности компаний. Так, в монографии [1, с. 15] дается следующее определение: «Финансовый потенциал следует понимать как некоторый уровень мощности, степень возможностей для обеспечения конкурентоспособности предприятия, обусловленные теми ресурсами, которые есть в распоряжении предприятия и способностью предприятия эффективно управлять данными ресурсами, т.е. их использовать и воспроизводить», а также приводится триадная шкала измерения уровня финансового потенциала (высокий, средний, низкий). Н.А. Сорокина считает, что «финансовый потенциал организации - это итоговая финансовая характеристика деятельности и одновременно стартовая оценка возможностей организации в ближайшем будущем, и влияние перечисленных групп факторов на финансовый потенциал существенно различается в зависимости от того, какую стратегию развития воплощает субъект бизнеса» [2, с. 15]. В статье Е.Ю. Макеевой и А.О. Бакуровой [3] отражено влияние финансового потенциала и прогнозирование его с использованием различных методов, а также определяется возможность прогнозирования банкротства компаний с учетом влияния различных внешних факторов.

Исследование направлено на то, чтобы выявить проблемы использования финансового потенциала компаний отрасли электроэнергетики и усовершенствовать процесс привлечения собственных, заемных и привлеченных источников финансирования для развития бизнеса, модернизации энергетической инфраструктуры, улучшения энергетической безопасности страны.

По нашему мнению, финансовый потенциал в исследуемой отрасли - это источник ресурсов электроэнергетических компаний, который аккумулируется в разделе «Капитал и резервы» бухгалтерского баланса (форма № 1). В структуре данного раздела одними из весомых элементов финансового потенциала выступают нераспределенная прибыль, уставный капитал и резервы компаний сферы электроэнергетики.

Эффективность финансового потенциала организаций электроэнергетики базируется на инвестиционной привлекательности российских компаний отрасли электроэнергетики для получения заемного капитала, которая в практике оценки корпоративных финансов определяется на основе соотнесения займов (суммы долгосрочных и краткосрочных обязательств) и собственного капитала, валюты (итога хозяйственного оборота) баланса.

Финансовый потенциал отрасли электроэнергетики раскрыт в научной литературе неполно, в ней прак- тически не затрагивается природа происхождения финансовых ресурсов. В этой связи необходимо раскрыть категорию «финансовый потенциал отрасли электроэнергетики».

Финансовый потенциал отрасли электроэнергетики наличие финансовых ресурсов компаний электроэнергетики, необходимых и достаточных для воспроизводства ресурсов топливно-энергетического комплекса, которые обеспечивают интенсификацию роста валового регионального продукта и оптимизацию стоимостной «цепочки добавленной стоимости» экологически чистых источников энергии как фактора энергетической безопасности отраслевой экономики.

В данном категориальном аппарате исследуется дефиниция «финансовые ресурсы компаний электроэнергетики», под которыми следует понимать совокупность накопленных денежных средств электроэнергетических предприятий, аккумулированных за счет различных источников финансирования и распределенных в инвестиционном портфеле отраслевых проектов посредством комбинации оптимальных элементов капитала: нераспределенной прибыли, резервного и добавочного капитала, амортизационного фонда и фонда развития энергетической промышленности, дивидендов на инвестированный капитал в уставные капиталы экономических агентов, страховых премий при осуществлении перестраховочных операций, доходов от аутсорсинга на рынке энергосбытовых услуг, иных собственных, привлеченных и заемных источников формирования имущества энергетического комплекса.

Финансовый потенциал отрасли электроэнергетики исследуется нами под углом зрения достаточности собственных и привлеченных, а также заемных источников финансирования, что предусматривает целесообразность конкретизации категорий «стоимость капитала» и «структура капитала». В ряде классических наук (финансы организаций, финансовый менеджмент, корпоративные финансы) под стоимостью капитала понимается цена как отдельно взятого элемента собственного капитала - обыкновенных акций, нераспределенной прибыли, амортизации внеоборотных активов, привилегированных акций или заемного капитала - банковского кредита, займа, финансовой аренды (лизинга), так и комплексного средневзвешенного показателя - цены капитала

$$
W A C C=\sum P_{i} \times Q_{i},
$$

где $W A C C$ - средневзвешенная стоимость капитала (источников финансирования);

$\sum$ - сумма произведений цены и удельного веса источников финансирования;

$P_{i}$ - цена капитала $i$-го вида, измеряемая в процентах или долях единиц;

$Q_{i}$ - удельный вес капитала $i$-го вида (в процентах или долях единиц). 
Рисунок 1. Динамика соотношения собственных и привлеченных средств в общем объеме инвестиций в основной капитал по коду деятельности ОКВЭД 2: (35) «Обеспечение электрической энергией, газом и паром; кондиционирование воздуха» в РФ в 2010-2017 гг.

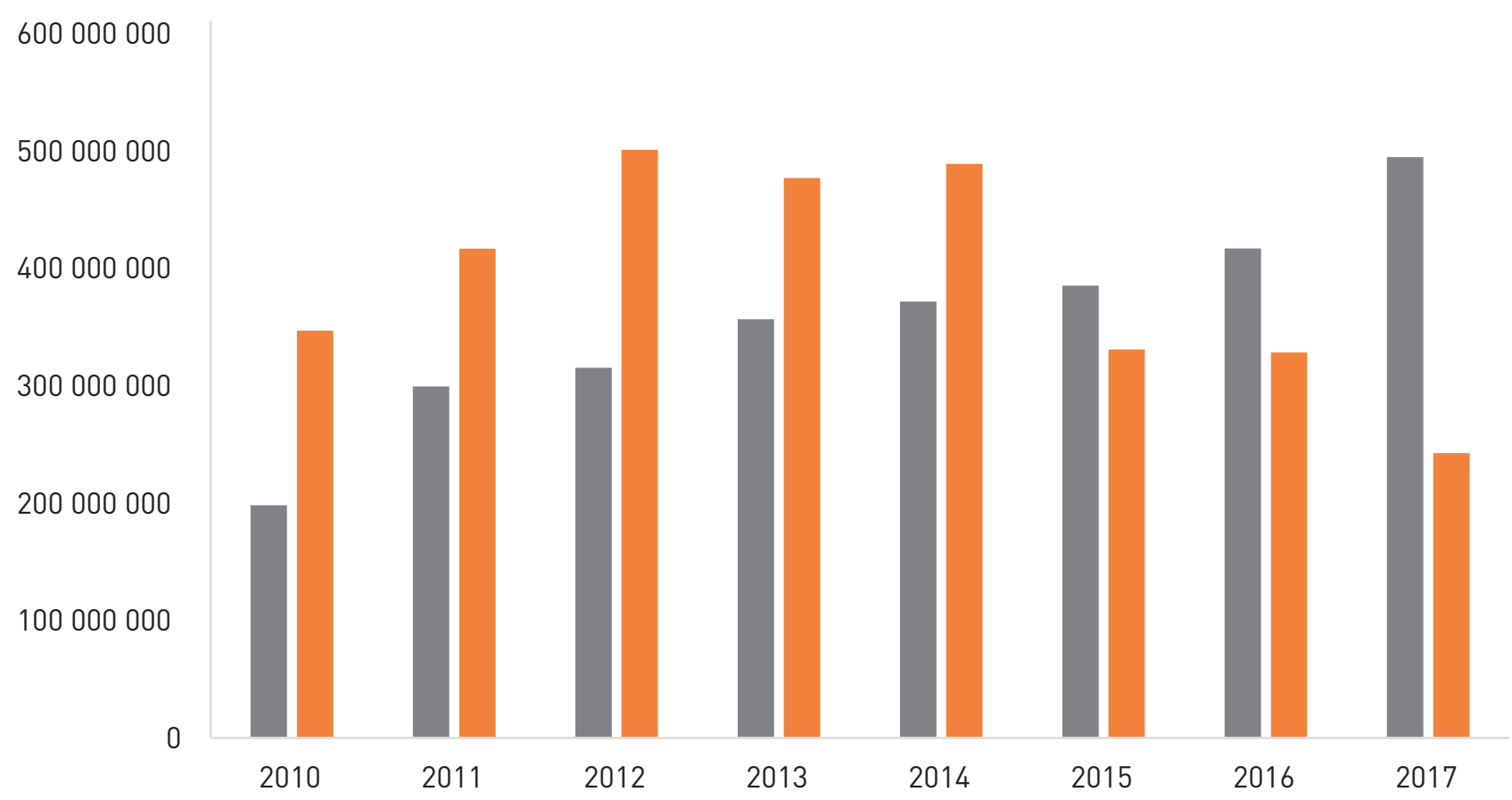

- Собственные средства, направленные на инвестиции в основной капитал, тыс. руб.

- Привлеченные средства, направленные на инвестиции в основной капитал, тыс. руб.

Источник: данные FIRA.

В практике оценки финансового потенциала отрасли электроэнергетики применяются три вида капитала: акционерный (собственный), заемный (банковское кредитование) и привлеченный, удельный вес определяется путем пропорционального распределения каждого вида источника финансирования деятельности электроэнергетических компаний в итоговой величине совокупного капитала. Цена конкретного вида капитала определяется установленной суммой затрат на его обслуживание. Например, компания отрасли электроэнергетики взяла кредит на установку энергосберегающего оборудования (удельный вес которого по расчетам финансово-экономического отдела достиг $40 \%$ в общей структуре источников финансирования) под 19\% годовых, следовательно, цена заемного капитала $P i$ равна 0,19, или $19 \%$, а удельный вес $Q i$ составит 0,4, или 40\%.

Важным при оценке финансового потенциала является определение возможностей привлечения инвестиций и инвестиционного потенциала отрасли для реализации проектов по расширению, диверсификации и модернизации отрасли электроэнергетики.
Выбор источников финансирования инвестиционных проектов логично связывать с документами стратегического планирования на федеральном и региональном уровнях, планами по реализации отраслевых проектов компаний-конкурентов в связи с высокими рисками. Качество подготовки вводных параметров при принятии решений по формированию инвестиционного плана и подготовке финансово-экономической модели прогнозирования отрасли напрямую влияет на инвестиционную привлекательность отрасли и сценарные условия развития отрасли электроэнергетики в кратко- и среднесрочной перспективе. Валидация используемых данных по объекту инвестирования и параметры результативности компаний отрасли электроэнергетики позволят обеспечить прогнозирование долгосрочных показателей эффективности и сроков окупаемости.

Следовательно, на конечный результат, обусловливающий достижение требуемого уровня инвестиционной привлекательности проекта, воздействует рациональное принятие решений в области наполнения стратегических моделей финансовой информацией. 
Таблица 1. Структура финансовых показателей по коду деятельности ОКВЭД 2: (35.11) «Производство электроэнергии» в $2013-2017$ гг., тыс. руб.

\begin{tabular}{|c|c|c|c|c|c|c|c|}
\hline Показатель & 2012 & 2013 & 2014 & 2015 & 2016 & 2017 & Изменение $(+,-)$ \\
\hline Валюта баланса, всего & 3750374889 & 3564913522 & 5049555235 & 5736072504 & 6091373417 & 6709061995 & 2958687106 \\
\hline Внеоборотные активы & 2567982509 & 2553484150 & 4112059879 & 4446696230 & 4420439437 & 4932034059 & 2364051550 \\
\hline Оборотные активы & 1182392380 & 1011429372 & 937495356 & 1289376274 & 1670933980 & 1777027936 & 594635556 \\
\hline Капитал и резервы & 2047561680 & 1853749724 & 3687765794 & 4208544061 & 4177012511 & 4837922079 & 2790360399 \\
\hline Задолженность по полученным кредитам и займам, всего & 570063171 & 684694224 & 999601937 & 1177779849 & 1279041952 & 1203896217 & 633833046 \\
\hline Структура баланса, \% & 100,00 & 100,00 & 100,00 & 100,00 & 100,00 & 100,00 & - \\
\hline Внеоборотные активы & 68,47 & 71,63 & 81,43 & 77,52 & 72,57 & 73,51 & 5,04 \\
\hline Оборотные активы & 31,53 & 28,37 & 18,57 & 22,48 & 27,43 & 26,49 & $-5,04$ \\
\hline Капитал и резервы & 54,60 & 52,00 & 73,03 & 73,37 & 68,57 & 72,11 & 17,51 \\
\hline Задолженность по полученным кредитам и займам, всего & 15,20 & 19,21 & 19,80 & 20,53 & 21,00 & 17,94 & 2,74 \\
\hline Выручка (нетто) от продажи & 1593682405 & 1590420949 & 1837204113 & 2020699277 & 2312087751 & 2487029873 & 893347468 \\
\hline Прибыль (убыток) до налогообложения & 106113100 & 124181244 & 104730026 & 142072099 & 375778401 & 373136434 & 267023334 \\
\hline
\end{tabular}

Источник: составлено авторами по данным FIRA.

Таблица 2. Структура инвестиций в основной капитал по коду деятельности ОКвЭД 2: (35) «Обеспечение электрической энергией, газом и паром; кондиционирование воздуха» в 2010-2017 гг., тыс. ру6.

\begin{tabular}{|c|c|c|c|c|c|c|c|c|}
\hline Показатель & 2010 & 2011 & 2012 & 2013 & 2014 & 2015 & 2016 & 2017 \\
\hline \multicolumn{9}{|l|}{ Российская Федерация } \\
\hline Собственные средства, направленные на инвестиции в основной капитал & 198087892 & 299249739 & 315242150 & 356517048 & 371520908 & 385209713 & 416755900 & 494550785 \\
\hline $\begin{array}{l}\text { Доля собственных средств, направленных на инвестиции в основной капитал к } \\
\text { общему объему инвестиций, \% }\end{array}$ & 36,35 & 41,80 & 38,63 & 42,78 & 43,18 & 53,80 & 55,94 & 67,10 \\
\hline Привлеченные средства, направленные на инвестиции в основной капитал & 346808003 & 416702806 & 500838940 & 476776396 & 488830116 & 330842711 & 328212999 & 242505667 \\
\hline $\begin{array}{l}\text { Доля привлеченных средств, направленных на инвестиции в основной капитал к } \\
\text { общему обвему инвестииий, \% }\end{array}$ & 63,65 & 58,20 & 61,37 & 57,22 & 56,82 & 46,20 & 44,06 & 32,90 \\
\hline \multicolumn{9}{|l|}{ в том числе привлеченные средства: } \\
\hline Кредиты банков, направленные на инвестиции в основной капитал, в том числе & 47598732 & 66316272 & 70371762 & 93419092 & 101267678 & 42003053 & 55959609 & 46480321 \\
\hline Доля кредитов банков в привлеченных средствах, \% & 13,72 & 15,91 & 14,05 & 19,59 & 20,72 & 12,70 & 17,05 & 19,17 \\
\hline Бюджетные средства, направленные на инвестиции в основной капитал & 31353553 & 28119705 & 30013324 & 23893556 & 45274472 & 36730890 & 29141357 & 18353119 \\
\hline Доля бюджетных средств в привлеченных средствах, \% & 9,04 & 6,75 & 5,99 & 5,01 & 9,26 & 11,10 & 8,88 & 7,57 \\
\hline Средства федерального бюджета, направленные на инвестиции в основной капитал & 24606497 & 22749165 & 25395784 & 17289766 & 41885489 & 29405264 & 17518929 & 11453479 \\
\hline Доля ФБ в привлеченных бюджетных средствах, \% & 78,48 & 80,90 & 84,62 & 72,36 & 92,51 & 80,06 & 60,12 & 62,41 \\
\hline $\begin{array}{l}\text { Средства бюджетов субъектов федерации, направленные на инвестиции в основной } \\
\text { капитал }\end{array}$ & 3613780 & 4845484 & 4025198 & 4084568 & 1517555 & 5284482 & 8334472 & 5576901 \\
\hline Доля РБ в привлеченных бюджетных средствах, \% & 11,53 & 17,23 & 13,41 & 17,09 & 3,35 & 14,39 & 28,60 & 30,39 \\
\hline $\begin{array}{l}\text { Прочие привлеченные средства, направленные на инвестиции в основной капитал, } \\
\text { mыс. руб. }\end{array}$ & 259623940 & 302563530 & 375696350 & 313095895 & 252447186 & 216391457 & 197092610 & 156216568 \\
\hline Доля прочих привлеченных средств в привлеченных средствах, \% & 74,86 & 72,61 & 75,01 & 65,67 & 51,64 & 65,41 & 60,05 & 64,42 \\
\hline $\begin{array}{l}\text { Заемные средства других организаций, направленные на инвестиции в основной } \\
\text { капитал }\end{array}$ & 8215925 & 19688077 & 24584761 & 45297528 & 64628405 & 20855538 & 34712786 & 21154212 \\
\hline Доля заемных средств других организаций в привлеченных средствах, \% & 2,37 & 4,72 & 4,91 & 9,50 & 13,22 & 6,30 & 10,58 & 8,72 \\
\hline
\end{tabular}

Доля заемных средств других организаций в привлеченных средствах, \% 2,37

9,50

10,58 


\section{Финансовый потенциал отрасли: анализ}

Таким образом, проведенное исследование выбора наиболее оптимального сочетания финансовых инструментов поддержки реального сектора экономики и стимулирования экономического роста в компаниях электроэнергетики направлено на устранение диспропорций в структуре выручки, капитала и других финансовых показателей развития отрасли (табл. 1).

Наблюдается положительная динамика роста собственного капитала в структуре баланса в 2012-2017 гг., но при этом также растет и задолженность по кредитам и займам, что требует оценки структуры инвестиций в отрасли электроэнергетики. Кроме того, определение инструментов финансирования отрасли реального сектора экономики с учетом прогнозов потребностей в инвестициях в разрезе регионов, способствует долгосрочному росту эффективности развития реального сектора экономики и повышению инвестиционной привлекательности компаний электроэнергетического комплекса России.

Обратимся к анализу структуры инвестиций в основной капитал по коду деятельности ОКВЭД 2:

(35) «Обеспечение электрической энергией, газом и паром; кондиционирование воздуха» в 2010-2017 гг. (табл. 2).
Согласно данным, приведенным на рис. 1, в 2017 г. объем собственных средств, направленных организациями на инвестиции в основной капитал по коду деятельности ОКВЭД 2: (35) «Обеспечение электрической энергией, газом и паром; кондиционирование воздуха», в целом по РФ составлял 494550785 тыс. руб. (на 77794885 тыс. руб. больше, чем в 2016 г.); привлеченных средств - 242505667 тыс. руб. (на 85707332 тыс. руб. меньше, чем в 2016 г.).

В течение всего отчетного периода 2010-2017 гг. в целом по РФ происходило постепенное увеличение собственных средств в структуре инвестиций в основной капитал по коду деятельности ОКВЭД 2: (35) при одновременном уменьшении объемов привлеченных средств. Так, если в 2010 г. на долю собственных средств приходилось $36,35 \%$ от общего объема инвестиций в основной капитал по коду деятельности ОКВЭД 2: (35), то в 2017 г. их доля составила $67,10 \%$, увеличившись в целом за анализируемый период 2010-2017 гг. на 30,74\%. Соответственно, доля привлеченных средств в общем объеме инвестиций в основной капитал по коду деятельности ОКВЭД 2: (35) уменьшилась с 63,65\% в 2010 г. до 39,20\% в 2017 г. Основным источником привлеченных средств, направленных на инвестиции в основной капитал по коду деятельности ОКВЭД 2: (35), в целом по РФ в течение всего анализируемого периода являлись прочие привлеченные средства, направленные на инвестиции в основной капитал (рис. 2).

Рисунок 2. Динамика соотношения источников привлеченных средств, направленных на инвестиции в основной капитал по коду деятельности ОКВЭД 2: (35) «Обеспечение электрической энергией, газом и паром; кондиционирование воздуха» в РФ в 2010-2017 гг., тыс. руб.

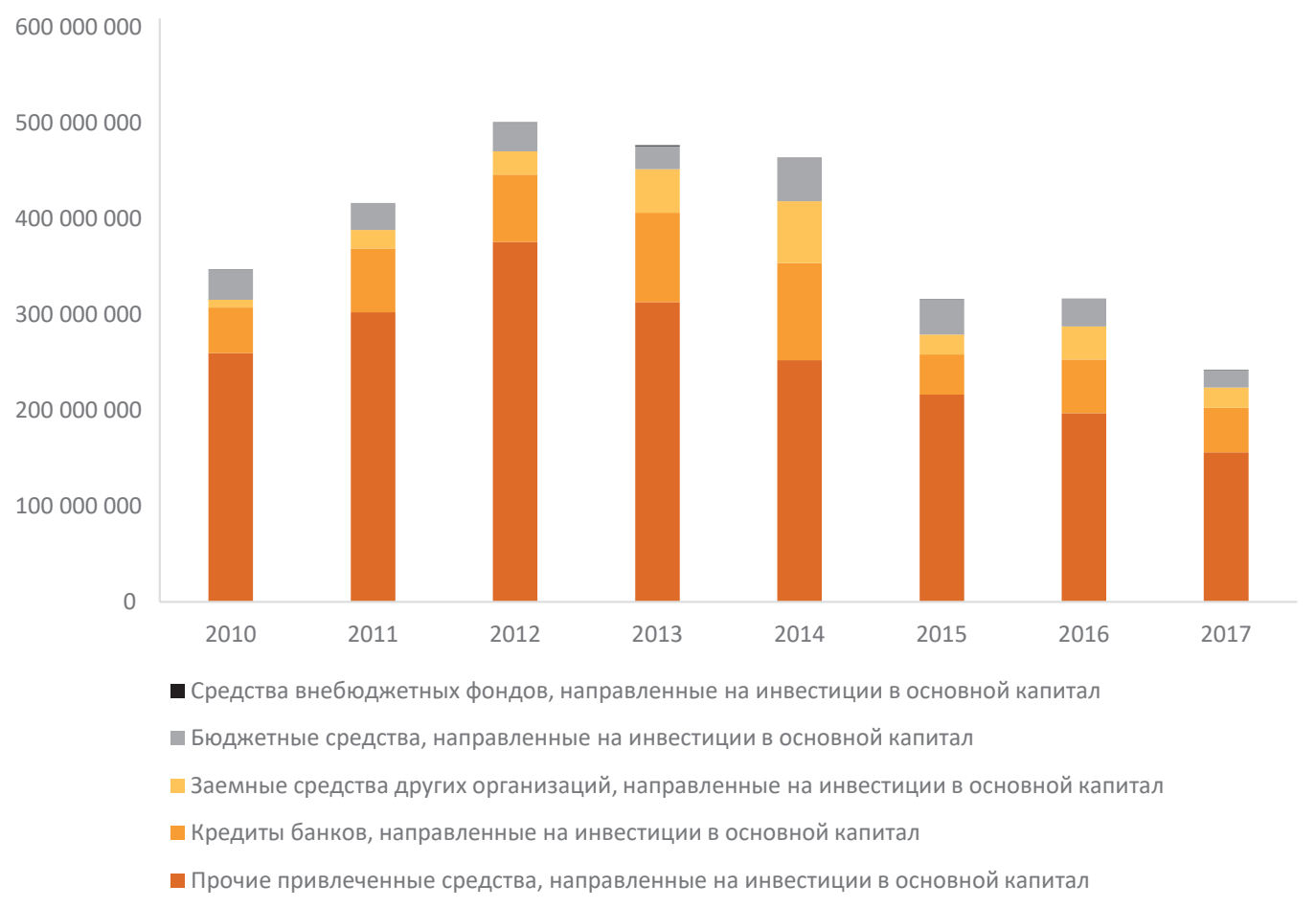

Источник: данные FIRA. 
Сравнительный анализ данных по соотношению источников привлеченных средств, направленных на инвестиции в основной капитал по коду деятельности ОКВЭД 2: (35), показал, что в 2017 г. объем прочих привлеченных средств составлял 156216568 тыс. руб. (снижение по сравнению с 2016 г. составило 40876042 тыс. руб.), или $64,42 \%$ от общего объема привлеченных средств, направленных на инвестиции в основной капитал по коду деятельности ОКВЭД 2: (35)).

Выявлен волнообразный тренд динамики объемов инвестиций в основной капитал по виду экономической деятельности производство и распределение электроэнергии, газа и воды в целом по Российской Федерации, характеризующийся ростом с 2010 по 2013 г. и снижением в 2014-2016 гг. При этом рост инвестиций в анализируемом периоде 2010-2017 гг. отмечался у всех составляющих инвестиций основного капитала за исключением категории «инвестиции в прочее». Анализ показал, что в течение всего отчетного периода 2010-2017 гг. в целом по РФ происходило постепенно увеличение собственных средств в структуре инвестиций в основной капитал в отрасли электроэнергетики при одновременном уменьшении объемов привлеченных средств. Аналогичная тенденция по увеличению объемов собственных средств и снижению объемов привлеченных средств в общем объеме инвестиций в основной капитал прослеживается во всех федеральных округах Российской Федерации.

\section{Финансовый потенциал отрасли: выводы и предложения}

Реализация инвестиционных программ организаций электроэнергетики напрямую связана с потребностью в модернизации и расширении производственных мощностей, стратегические приоритеты развития отрасли определены на федеральном уровне, но в условиях влияния внешних санкций, низкой нормы прибыльности и дорогих источников финансирования требуется оценка структуры и конкурентоспособности рынка электроэнергетики. Проведенный анализ показал, что наряду с проблемой наличия иссякающих запасов нефти и газа российская экономика сталкивается с новой реальностью, для которой характерны факты нерационального и несбалансированного использования инвестиций в сфере функционирования энергетического комплекса страны. В связи с изложенным представляется, что в целях предупреждения фактов возникновения аварийности на объектах электроэнергетики, снижения рисков необоснованной системы тарификации и ценообразования на продукцию и услуги монополистов в сфере энергетики, повышения качества планирования инвестиций, целесообразно заблаговременно планировать и прогнозировать источники финансирования инвестиционных программ в компаниях энергетического комплекса.

Следует отметить, что натуральные показатели оценки, влияющие на финансовый потенциал отрасли электроэнергетики - передача, продажа и диспетчеризация энергоресурсов, определяют производственный потенциал компаний, а денежные индикаторы (стоимость капитала и выручка от продаж) характеризуют устойчивость пассивов энергетических компаний к различного рода финансовым деформациям. Таким образом, управляя натуральными, стоимостными и производственными параметрами функционирования энергетического комплекса на интегрированной основе, можно повысить финансовый потенциал компаний в перспективе.

Российские реалии указывают на возникновение ряда трудностей, которые заключаются в отсутствии «длинных денег» в реальном и банковском сектоpax. Кроме того, Россия находится в условиях новой экономической реальности, для которой свойственны факты падения объемов продаж на рынке углеводородов, влияние санкций, что требует внедрения новых драйверов экономического развития, для запуска которых необходимы НИОКР, диверсификация портфеля инвестиционных проектов и проектные команды способные эти проекты реализовать.

По нашему мнению, систематизированные в ходе исследования меры использования ресурсов банковского и небанковского секторов экономики ориентируют инвесторов в выборе гибких моделей управления финансовыми активами. Однако, как представляется, проблема дефицита источников финансового обеспечения энергетического комплекса нуждается в комплексном решении и не может быть реализована без выбора оптимальных инструментов финансирования реального сектора экономики.

В качестве перспективных источников финансирования, в том числе энергетического комплекса, предлагаются: проектное финансирование при строительстве новых энергоисточников, корпоративное кредитование долгосрочных инвестиционных проектов, перформанс-контракты, использование инструментов рынка «зеленого» финансирования. Вместе с тем рекомендуется учитывать, что использование того или иного источника финансирования имеет как положительные, так и отрицательные моменты, которые должны учитываться при разработке инвестпроектов.

Ключевым недостатком также является отсутствие методики оценки инвестиционной привлекательности отрасли электроэнергетики при огромном многообразии методов оценки применительно к организациям (фирмам): cash-flow, рейтинговые и интегральные, оценка ликвидности и финансовой устойчивости и ряд других.

Исходя из вышеизложенного, предлагается расширить существующие методики оценки инвестиционной привлекательности отрасли электроэнергетики (табл. 3) показателем удельного веса чистых активов в объеме финансового потока и методическими рекомендациями по формированию конкурентного механизма финансирования компаний электроэнергетики. 
Таблица 3. Сравнение показателей инвестиционной привлекательности российских компаний электроэнергетики до и после внедрения новой методики

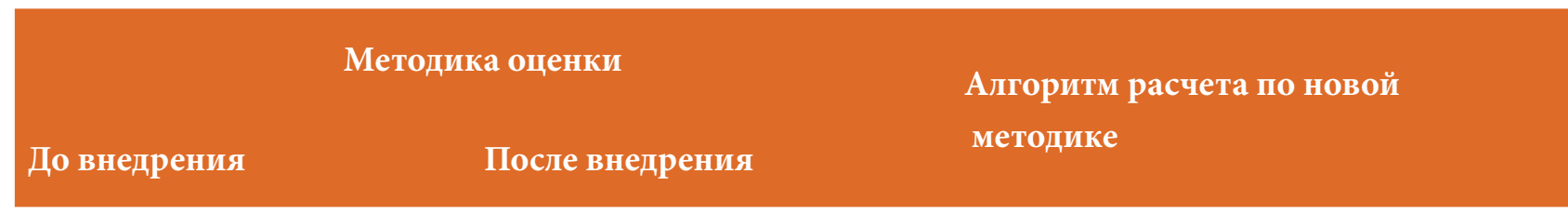

$\begin{array}{ll}\begin{array}{l}\text { Рентабельность } \\ \text { капитала }\end{array} & \begin{array}{l}\text { Доля издержек в объеме } \\ \text { прибыли }\end{array}\end{array} \begin{aligned} & \text { Отношение затрат и поступлений } \\ & \text { денежных средств }\end{aligned}$

$\begin{array}{ll}\text { Рентабельность } & \text { Удельный вес чистых активов в } \\ \text { продаж } & \text { объеме финансового потока }\end{array}$

Чистые активы по отношению к объему поступлений (по показателю финансового потока)

\section{Оборачиваемость}

активов

Коэффициент ликвидности
Доля текущей стоимости оборотных активов в объеме кредиторской задолженности

\section{Финансовый \\ рычаг}

\section{Рентабельность чистых активов по критериям прибыли и чистых активов}

Отношение прибыли к стоимости чистых активов

Источник: составлено на основе [6, 7].

Рисунок 3. Модели гибкого развития и финансирования компаний реального сектора экономики (на примере компаний электроэнергетики)

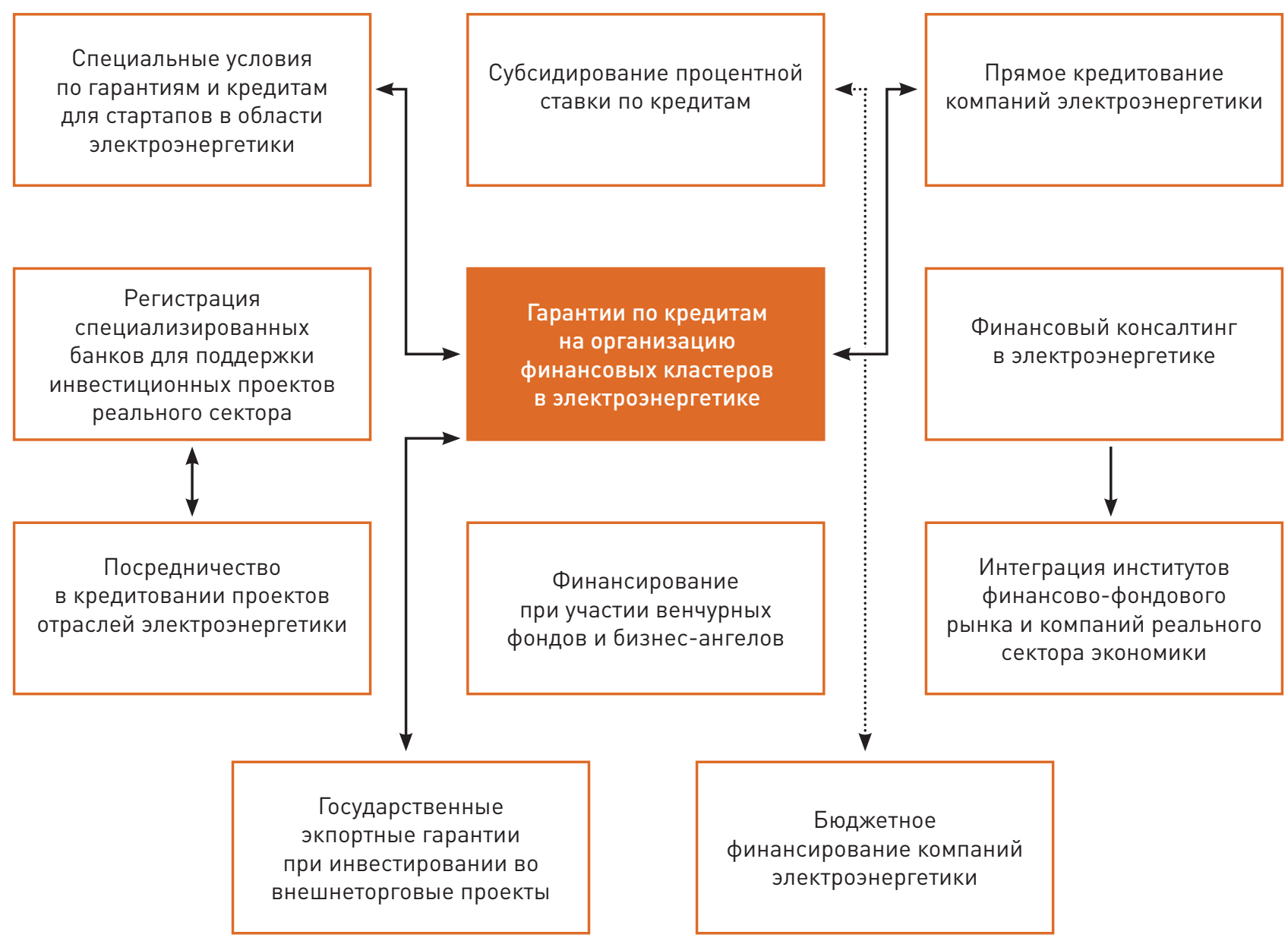

Источник: составлено автором на основе $[4,5]$. 
Необходимо отметить, что предлагаемые методические рекомендации по формированию конкурентного механизма финансирования компаний электроэнергетики учитывают:

1) возможность одновременного финансирования нескольких инвестиционных программ.

Для российских компаний электроэнергетики в долгосрочной перспективе будет свойственно увеличение доли чистых активов в объеме финансового потока от реализации энергетических ресурсов. При этом расчет представленного коэффициента предлагается нами осуществлять посредством соотнесения чистых активов и объема выручки (операционных доходов, инвестиционных притоков) и иных положительных потоков, способствующих формированию долгосрочных финансовых преимуществ в сфере функционирования отрасли;

2) роль государственных органов исполнительной власти в вопросах регулирования минимальных границ инвестиционных вложений в отрасль электроэнергетики, направленные на устранение неоднородности инфляционных процессов при прогнози- ровании цен и снижении рисков государственного и частного взаимодействия при создании дополнительных инструментов финансирования.

Модели гибкого развития и финансирования компаний реального сектора экономики (рис. 3) с учетом лучшей зарубежной практики могут быть представлены в следующей форме организационных мер.

По нашему мнению, модель гибкого развития может быть направлена на расширение мероприятий по инвестированию в отрасль электроэнергетики как для регионов, так и на федеральном уровне, и на повышение финансового потенциала компаний - инициаторов проекта. Однако для этого требуется разработать комплекс мер по стимулированию инициатив как в электроэнергетике, так и в смежных отраслях экономики, направленных на решение задач энергосбережения и экологии.

В табл. 4 представлен разработанный авторами статьи формат методических рекомендаций по формированию конкурентного механизма финансирования компаний реального сектора экономики.

Таблица 4. Методические рекомендации по формированию конкурентного механизма финансирования компаний реального сектора экономики (на примере предприятий электроэнергетики)

\section{Инструменты Задачи по формированию конкурентного механизма финансирования}

\begin{tabular}{|c|c|c|c|c|}
\hline Налоговые & $\begin{array}{l}\text { Формирование инфра- } \\
\text { структуры исследователь- } \\
\text { ских центров, допол- } \\
\text { няющих существенные } \\
\text { научные организации и } \\
\text { университеты }\end{array}$ & $\begin{array}{l}\text { Применение налого- } \\
\text { вых льгот, льготных } \\
\text { платежей за единицу } \\
\text { мощности произве- } \\
\text { денной возобновляе- } \\
\text { мой энергии }\end{array}$ & $\begin{array}{l}\text { Снижение нало- } \\
\text { говых платежей } \\
\text { при реализации } \\
\text { возобновляемой } \\
\text { электроэнергии }\end{array}$ & $\begin{array}{l}\text { Внедрение комби- } \\
\text { нированных форм } \\
\text { государственного } \\
\text { финансирования, в } \\
\text { том числе: прямое } \\
\text { субсидирование и } \\
\text { грантовая поддержка }\end{array}$ \\
\hline $\begin{array}{l}\text { Государствен- } \\
\text { ной экономи- } \\
\text { ческой поли- } \\
\text { тики }\end{array}$ & $\begin{array}{l}\text { Методика независимой } \\
\text { финансово-экономиче- } \\
\text { ской оценки обоснован- } \\
\text { ности процедур регули- } \\
\text { рования деятельности } \\
\text { предприятий электроэ- } \\
\text { нергетики }\end{array}$ & $\begin{array}{l}\text { Формирование } \\
\text { конкурентного } \\
\text { внутреннего рынка } \\
\text { научно-технических } \\
\text { работ }\end{array}$ & $\begin{array}{l}\text { Привлечение } \\
\text { частных инве- } \\
\text { стиций из фон- } \\
\text { дов страховых } \\
\text { компаний }\end{array}$ & $\begin{array}{l}\text { Совершенствование } \\
\text { мер тарифного регу- } \\
\text { лирования и квоти- } \\
\text { рования для возоб- } \\
\text { новляемой энергии }\end{array}$ \\
\hline
\end{tabular}

Инновацион- Методика экономической оценки программ развития предприятий электроэнергетики ного развития

\begin{tabular}{|c|c|c|c|c|}
\hline $\begin{array}{l}\text { Государствен- } \\
\text { но-частного } \\
\text { партнерства }\end{array}$ & $\begin{array}{l}\text { Финансовая кластериза- } \\
\text { ция отраслевой эконо- } \\
\text { мики }\end{array}$ & $\begin{array}{l}\text { Предоставление } \\
\text { гарантий возврата } \\
\text { вложенных инвести- } \\
\text { ций в масштабах ре- } \\
\text { ализации региональ- } \\
\text { ных и федеральных } \\
\text { целевых программ по } \\
\text { обеспечению внедре- } \\
\text { ния генерирующих } \\
\text { объектов }\end{array}$ & $\begin{array}{l}\text { Совершенство- } \\
\text { вание законо- } \\
\text { дательной базы } \\
\text { в части опреде- } \\
\text { ления предмета } \\
\text { контрактных } \\
\text { отношений в } \\
\text { рамках финан- } \\
\text { совой кластери- } \\
\text { зации }\end{array}$ & $\begin{array}{l}\text { Перекрестное субси- } \\
\text { дирование в рамках } \\
\text { государственно-част- } \\
\text { ного партнерства } \\
\text { сегментов кластера, } \\
\text { создаваемого в инте- } \\
\text { ресах деятельности } \\
\text { предприятий элек- } \\
\text { троэнергетики }\end{array}$ \\
\hline
\end{tabular}

Источник: составлено авторами на основе [8]. 
Оценка данных табл. 4 позволяет выделить четыре типа инструментов финансирования, которые, по нашему мнению, следует применять для совершенствования деятельности компаний реального сектора экономики: инструменты ГЧП, инновационного развития, государственной экономической политики и фискальные инструменты. При этом одной из задач реализации фискальных инструментов финансирования электроэнергетики России является формирование инфраструктуры исследовательских центров, осуществляющих разработку и внедрение «прорывных» технологических проектов.

Ключевой задачей государственной экономической политики в сфере финансирования, на наш взгляд, является совершенствование мер тарифного регулирования и квотирования для возобновляемой энергии. Это позволит усовершенствовать механизм кругооборота энергетических ресурсов и повысить уровень финансовой безопасности энергетических компаний. В масштабах практики реализации ГЧП представляется необходимой организация мер по финансовой кластеризации отраслевой экономики.

Следует отметить, что для адаптации методических рекомендаций по формированию конкурентного механизма финансирования к компаниям электроэнергетики, по нашему мнению, необходимо использовать следующие методы оценки: эвристические, индексный и методы сравнительных оценок; компонентный и трендовый анализ, теорию игр.

Порядок адаптации методических рекомендаций состоит в расчете в два этапа.

1) На первом этапе производится комплексная (общая) оценка эффективности инвестиционной программы компаний электроэнергетики. Данный этап является промежуточным, обеспечивая информационно-аналитическую подготовку принятия решений о схеме финансирования.

2) На втором этапе аргументируется вывод о целесообразности привлечения соответствующего источника финансирования. При реализации второго этапа учитываются отраслевые документы, регламентирующие вопросы финансирования, структуры инвестиций и требований к инвесторам.

Таким образом, анализ и исследование потенциала отраслей электроэнергетики позволили установить характер взаимоотношений отраслевых компаний и частных инвесторов, государства и главных распорядителей бюджетных средств.

В рамках разработанной схемы подчинения частных и государственных структур определены критерии оценки и инструкции, алгоритмы адаптации методик формирования конкурентного финансового механизма. Это позволит, с одной стороны, достичь реализации задач государственной энергетической политики, и, с другой стороны, обеспечить удовлетворение потребностей инвесторов в оптимальном балансе между вкладываемым капиталом в проекты электроэнергетики и получаемой отдаче в виде долговременной чистой прибыли.

Кроме того, адаптация методических рекомендаций к компаниям реального сектора экономики с учетом оценки потенциального развития в долгосрочной перспективе предполагает использование стратегического управления конкурентными преимуществами финансового механизма аккумулирования потоков доходов для компаний электроэнергетики. При этом важно выработать рациональную функциональную структуру, модель гибкого планирования бюджета и оценки ключевых рисков, возникающих не только на микроуровне, но и на мезо- и макроуровнях экономического развития.

\section{Список литературы}

1) Павлов А.Ю., Батова В.Н., Юдаева Н.Ю. Финансовый потенциал организаций в отраслях и сферах деятельности. Пенза: ПензГТУ, 2018.

2) Сорокина Н.А. Финансовый потенциал коммерческих организаций: модели и факторы. Известия Иркутской государственной экономической академии. 2011;(6):15.

3) Макеева Е.Ю., Бакурова А.О. Прогнозирование банкротства компаний нефтегазового сектора с использованием нейросетей. Корпоративные финансы. 2012;6(3):22-30. DOI: 10.17323/j. jcfr.2073-0438.6.3.2012.22-30.

4) Развитие малого и среднего предпринимательства. Зарубежный опыт. М.: ВЭБ. МСП Банк; 2015. Декабрь. 23 с. URL: https:// www.slideshare.net/steveas/2015-77610641

5) Дятлов С.А. Энтропийная экономика: методология исследования глобального кризиса. М.: ИНФРА-М; 2017. 350 с.

6) Бадалов А.Л. Развитие методологии управления инвестиционной деятельностью в компаниях топливно-энергетического комплекса. Автореф. дисс. ... докт. экон. наук. М.: РЭА им. Г.В. Плеханова; 2009. 36 с.

7) Шеремет А.Ф. Теория экономического анализа. 3-е изд. М.: ИНФРА-М; 2017. 352 с.

8) Проскурякова Л.Н., Ермоленко Г.В. Возобновляемая энергетика 2030: глобальные вызовы и долгосрочные тенденции инновационного развития. М.: НИУ ВШЭ; 2017. $96 \mathrm{c.}$

9) Kosov M.E., Akhmadeev R.G., Smirnov D.A., Solyannikova S.P., Rykova I.N. Energy industry: Effectiveness from innovation. International Journal of Energy Economics and Policy. 2018;8(4):83-89.

10) Barlow M.T. A diffusion model for electricity prices. Mathematical Finance. 2002;12(4):287-298. DOI: 10.1111/j.1467-9965.2002.tb00125.x 
11) Kuzmin E.A., Volkova E.E., Fomina A.V. Research on the concentration of companies in the electric power market of Russia. International Journal of Energy Economics and Policy. 2019;9(1):130-136. DOI: 10.32479/ijeep.7169

12) Krizanic F., Oplotnik Z.J. Factors of electricity prices in selected EU member states after the financial crisis and during significant market distortions. International Journal of Energy Economics and Policy. 2017;7(2):250-254.

13) Smagulova S.A., Omarov A.D., Imashev A.B. The value of investment resources influx for the development of the electric power industry of Kazakhstan. International Journal of Energy Economics and Policy. 2015;5(1):374-384.
14) Alinsato A.S. Economic valuation of electrical service reliability for households' in developing country: A censored random coefficient model approach. International Journal of Energy Economics and Policy. 2015;5(1):360-373.

15) Léautier T.-O. Electricity auctions. Journal of Economics and Management Strategy. 2001;10(3):331358. DOI: 10.1111/j.1430-9134.2001.00331.x 


\section{Improving Tools}

\section{for Assessing Financial Capacity in the Electric Power Industry}

Inna Rykova

Doctor of Economics, Head of the Sectorial Economy Center

ORCID

E-mail: rycova@yandex.ru

Sectorial Economy Center, "Financial Research Institute”, Moscow, Russia

Denis Taburov

$\mathrm{PhD}$ (Engineering), Senior Researcher

ORCID

E-mail: taburov@narod.ru

Sectorial Economy Center, "Financial Research Institute", Moscow, Russia

Journal of Corporate Finance Research, Vol. 13, No. 1, pp. 93-106 (2019)

DOI: https://doi.org/10.17323/j.jcfr.2073-0438.13.1.2019.93-106

Received 18 October 2018 | Peer-reviewed 15 December 2018 | Accepted 5 March 2019 


\section{Improving Tools for Assessing Financial Capacity in the Electric Power Industry}

\section{Abstract}

This study is dedicated to estimating the impact of currency risk on the cost of equity in Brazil, Russia, India and South Africa. Our contribution to the literature is that we have obtained evidence on the pricing of exchange rate risk in developing countries, which at the time of writing is quite scarce. This scarcity is one motivation for our research, which is dedicated to BRICS capital markets, though with the Chinese stock market excluded since it is heavily regulated. The aim of this research is to determine whether in emerging countries stock markets currency risk is a significant factor that influences the cost of equity capital in a company.

Changes in the value of exchange rates can impact the cash flows of a firm and its exposure to risk, and hence, the value of the company. In our research we will discuss the influence of exchange rate movements on the value of firms through their impact on the cost of equity. Specifically, we investigate whether companies that report substantial currency gains or losses have to pay a higher required rate of return on equity. Furthermore, in this study we make an attempt to estimate currency risk premia for exposure to appreciation and depreciation of currency separately, and try to identify possible differences.

For each country, three analytical models that extend the Fama-French Three Factor Model (by incorporating currency risk) are estimated. We use an equal-weighted portfolio approach to identify currency risk factors. These factors are estimated either by using information about the ratio of currency gains to sales, or the magnitude of covariation between equity returns and exchange rate changes. In the second case appreciation and depreciation of domestic currency against the US dollar is considered separately.

The results indicate that in Russia, firms which report substantial currency losses pay a positive risk premium, while in Brazil, India and South Africa companies with significantly positive or negative currency gains pay a lower required return on equity than firms with almost zero currency gains. Finally, we attempt to explain the estimation results using a sectoral breakdown of product exports for each country of the data sample.

Keywords: exchange rate exposure, cost of equity, currency markets, stock returns, emerging markets JEL classification: G12, G32 


\section{References}

1) Pavlov A.Yu., Batova V.N., Yudaeva N.Yu. Financial potential of organizations in industries and fields of activity. Penza: Penza STU; 2018. (In Russ.).

2) Sorokina N.A. Financial potential of commercial organizations: Models and factors. Izvestiya Irkutskoi gosudarstvennoi ekonomicheskoi akademii = Izvestiya of Irkutsk State Economics Academy. 2011;(6):15. (In Russ.).

3) Makeeva E.Yu., Bakurova A.O. Forecasting bankruptcy of oil and gas companies using neural networks. Korporativnye finansy $=$ Journal of Corporate Finance Research. 2012;6(3):22-30. DOI: 10.17323/j.jcfr.2073-0438.6.3.2012.22-30. (In Russ.).

4) Development of small and medium-sized businesses. Foreign experience. Moscow: VEB. SME Bank; 2015. December. 23 p. URL: https://www.slideshare.net/ steveas/2015-77610641 (In Russ.).

5) Dyatlov S.A. Entropic economics: Methodology of global crisis research. Moscow: INFRA-M, 2017. 350 p. (In Russ.).

6) Badalov A.L. Development of investment management methodology in companies of the fuel and energy complex. Doct. econ. sci. diss. Synopsis. Moscow: Plekhanov Russian Academy of Economics; 2009. 36 p. (In Russ.).

7) Sheremet A.F. Theory of economic analysis. $3^{\text {rd }}$ ed. Moscow: INFRA-M; 2017. 352 p. (In Russ.).

8) Proskuryakova L.N., Ermolenko G.V. Renewable energy 2030: global challenges and long-term trends of innovative development. Moscow: HSE Publ.; 2017. 96 p.
9) Kosov M.E., Akhmadeev R.G., Smirnov D.A., Solyannikova S.P., Rykova I.N. Energy industry: Effectiveness from innovation. International Journal of Energy Economics and Policy. 2018;8(4):83-89.

10) Barlow M.T. A diffusion model for electricity prices. Mathematical Finance. 2002;12(4):287-298. DOI: 10.1111/j.1467-9965.2002.tb00125.x

11) Kuzmin E.A., Volkova E.E., Fomina A.V. Research on the concentration of companies in the electric power market of Russia. International Journal of Energy Economics and Policy. 2019;9(1):130-136. DOI: 10.32479/ijeep.7169

12) Krizanic F., Oplotnik Z.J. Factors of electricity prices in selected EU member states after the financial crisis and during significant market distortions. International Journal of Energy Economics and Policy. 2017;7(2):250-254.

13) Smagulova S.A., Omarov A.D., Imashev A.B. The value of investment resources influx for the development of the electric power industry of Kazakhstan. International Journal of Energy Economics and Policy. 2015;5(1):374-384.

14) Alinsato A.S. Economic valuation of electrical service reliability for households' in developing country: A censored random coefficient model approach. International Journal of Energy Economics and Policy. 2015;5(1):360-373.

15) Léautier T.-O. Electricity auctions. Journal of Economics and Management Strategy. 2001;10(3):331358. DOI: 10.1111/j.1430-9134.2001.00331.x 